Military Technical College

Kobry El-Kobba

Cairo, Egypt

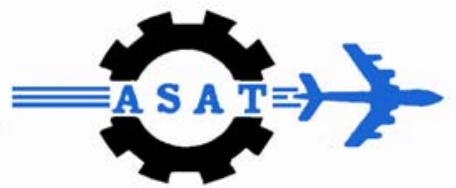

12-th International Conference

on

Aerospace Sciences \&

Aviation Technology

\title{
PERFORMANCE STUDY AND SYSTEM CAPACITY ANALYSIS OF A TWO-TIER CDMA SYSTEM
}

\author{
F. Khalifa*, S. Kishk**, and F. Zaki***
}

\begin{abstract}
One of the main factors that affects the performance of a Code Division Multiple Access (CDMA) system is the out of-cell interference. While the in-cell interference is controlled within each cell using a power control algorithm, the out of -cell interference is not and can greatly impact network coverage and the total user capacity, so that CDMA capacity is an interference limited capacity. One design technique to reduce the effect of the out of-cell interference in cellular CDMA systems is to use cells of different radii, hierarchically organized in overlapping layers, this is the multitier system. In This paper the user capacity on the reverse link direction of a certain two-tier CDMA system that consists of a small microcell embedded in a larger macrocell, i.e. a two cell system is examined. The effect of the users' mobility on the call blocking and call dropping probabilities is examined depending on the system feasibility. The simulation results show that at different call arrival rates the system capacity is increased as compared with the previous work. The dominant parameters affecting the system performance are the users' velocity and the distance between the two cells.
\end{abstract}

Key-Words: - CDMA, multitier systems, power control, hierarchically, call admission , and feasibility

\footnotetext{
*MSc. Student, Electronics and Communications Eng. Dpt., Mansoura University, Mansoura, Egypt ${ }^{* *}$ Assistance prof. Electronics and Communications Eng. Dpt., Mansoura University, Mansoura, Egypt ${ }^{* * *}$ Professor, Electronics and Communications Eng. Dpt., Mansoura University, Mansoura, Egypt
} 


\section{Introduction}

As the number of mobile subscribers' increases, this puts the wireless operators in challenge to provide their customers with a better quality of service (QoS), and in the same time support a large number of mobile users under the limited spectrum resources. This ensures the possibility and availability of anytime anywhere communication to the mobile system users [1]

One of the important issues addressed in CDMA systems is the Macro / Microcellular architecture or two-tier systems. Such systems consist of macrocells in which microcells are embedded. These low-cost, low-power microcells bases are installed to provide coverage to small regions of high-traffic [2]. This architecture enhances the total capacity of CDMA system [3].

In this paper the uplink capacity of a two tier CDMA system like that used in [4] is examined, but unlike the previous work $[1,4]$ on such a system the effect of users' mobility on the total system capacity is taken into consideration, and the results are compared with that in [4]. The uplink direction only is examined because it tends to be the limiting direction [5]. Due to the computational complexity for the user mobility encountered in system capacity analysis, the system performance is examined by computer simulation.

\section{System Model}

Consistence with the previous published work of the two -tier systems [1,4], a simple two cell CDMA system is considered as shown in Fig.1, it consists of a single microcell embedded in a larger macrocell to provide service and coverage to mobile users with high traffic density in the microcell zone, this system is considered through out this work with the same specifications as in [1]

\section{A. Propagation Model}

Propagation attenuation is modeled as the product of the $a^{\text {th }}$ power of distance $d$ between the mobile user and the base station (BS) and a component representing the shadowing effects of buildings and hills, this is generally adopted in mobile radio propagation models [6]. A composite profile for the path loss exponent is considered, i.e., $\alpha=2$ for shorter distances (i.e., $d<d_{b}$ ) and $\alpha=4$ for longer distances( i.e., $d \geq d_{b}$ ) [7], and the shadowing component is generally modeled as $10^{\zeta / 10}$ where $\zeta$ is the $\mathrm{dB}$ attenuation due to shadowing, with zero mean and standard deviation $\sigma$. The path gain between the mobile station (MS) and its serving (BS) is given by,

$$
P_{L}=G\left(\frac{d_{b}}{d}\right)^{a} \cdot 10^{\zeta / 10}
$$


Where $d_{b}$ is the break point at which the path gain is changed, and $G$ is the propagation constant, which is determined by the BS antenna height, MS antenna height, and wavelength (i.e. carrier frequency).

\section{Link Capacity of a two-cell System}

Kishore et. al. $[1,4]$ studied a similar system to the one reported here and found the total number of users to be served in two different approaches. In the first approach they found all possible combinations of macrocell users, $\mathrm{N}_{1}$, and Microcell users, $\mathrm{N}_{2}$, that can be served simultaneously without call blocking with a given probability of success at different hotspot densities $\left(P_{\mu}\right)$. In the second approach they found the total system capacity $N_{t}$ for different system states and different tier selection methods. From the results in $[1,4]$ it was shown that the maximum achieved number of users supported in the system was around 38 users at $P_{\mu}=0.5$.

In this paper, and extension of the work reported above is conducted, where the user mobility is considered in evaluating the system performance. To carry on this study, the uplink Signal-to-Interference ratio (SIR) at both cells is given by [4] as

$$
\begin{aligned}
& S_{I}=\frac{S_{r 1} \cdot P G}{N_{P}+\left(N_{1}-1\right) S_{r 1}+S_{r 2} I_{21}} \\
& S_{R}=\frac{S_{r 2} \cdot P G}{N_{P}+\left(N_{2}-1\right) S_{r 2}+S_{r 1} I_{12}}
\end{aligned}
$$

Where $N_{1}$, and $N_{2}$ are the number of active users in both cells, $I_{21}$, and $I_{12}$ are the normalized cross tier interference caused by microcell and macrocell users at the macrocell $B S$ and microcell BS respectively [1], and $P G$ is the system processing gain, $P G=W / R_{b}$,

A minimum value of SIR for all users in the system is required to maintain the acceptable QoS these values are $\Gamma_{1}$ and $\Gamma_{2}$, for users in the two cells respectively. The required Eb/No for uplink in CDMA systems is approximately $7 \mathrm{~dB}$, if the bit error rate is less than $10^{-3}$ [6]. The desired signal power level at both bases is found to be $[1,4]$.

$$
\begin{aligned}
& S_{r 1}=N_{P} \frac{\left(C_{2}-N_{2}\right)+I_{21}}{\left(C_{1}-N_{1}\right)\left(C_{2}-N_{2}\right)+I_{21} \cdot I_{12}} \\
& S_{r 2}=N_{P} \frac{\left(C_{1}-N_{1}\right)+I_{12}}{\left(C_{1}-N_{1}\right)\left(C_{2}-N_{2}\right)+I_{21} \cdot I_{12}}
\end{aligned}
$$


Where $C_{j}=P G^{*} \Gamma+1$ the maximum single cell capacity [8], and $N_{P}$ is the receiver noise power which is modeled as AWGN with spectral density of $\eta$ and is assumed to be the same at both bases

The system capacity is determined as long as both $S_{r 1}$ and $S_{r 2}$ are positive, i.e., there is a feasible solution [1]. In analyzing the system performance the following assumptions are made:

(1)Each user in the environment is processed by only one base, his cell membership is determined according to the base station to which it has a higher path gain, and as users move over the terrain their path gains change so they have to reconsider their cell membership every second of their conversation ;

(2)Macrocell and microcell users have a random velocity $U_{1}$ and $U_{2}$ respectively, a random direction $\theta$, and a random call time CT.

(3)The traffic density in the microcell is $\mathrm{P}_{\mu} \%$ of the total traffic in the system

(4)The call arrival rate to the system is considered to be a Poisson distributed random variable with mean $\lambda$ and arrived to the system with the same probability $P_{\mu}$.

(5) The proposed call admission scheme used in this work is shown in Fig.2.

(6)A new user is admitted to the system if and only if there is a feasible power solution for currently active user if the new admitted user leads to a feasible solution it will be accepted, but if contrary it will be blocked.

\section{Numerical Results and Discussion}

To examine the uplink capacity of the two-cell system, call blocking, and call dropping probability for the proposed scheme, the parameters listed in table 1. are used along with the assumptions of section III. Moreover it is assumed that the traffic load of the microcell is $50 \%$ of the maximum traffic allowed in the system i.e., $\mathrm{P}_{\mu}=0.5$ for most of this work.

Table1. Simulation parameters

\begin{tabular}{|c||c|c|c||}
\hline $\mathrm{W}$ & $1.28 \mathrm{MHz}$ & $\sigma_{1}$ & $8 \mathrm{~dB}$ \\
$\mathrm{R}_{\mathrm{b}}$ & $9.6 \mathrm{Kbps}$ & $\sigma_{2}$ & $4 \mathrm{~dB}$ \\
$\mathrm{~L}_{1}$ & $1000 \mathrm{~m}$ & $\mathrm{U}_{1}$ & $0: 5 \mathrm{~m} / \mathrm{s}$ \\
$\mathrm{L}_{2}$ & $200 \mathrm{~m}$ & $\mathrm{U}_{2}$ & $0: 2 \mathrm{~m} / \mathrm{s}$ \\
$\mathrm{R}_{0}$ & $300 \mathrm{~m}$ & $\mathrm{CT}$ & $1: 120 \mathrm{~s}$ \\
$\mathrm{~h}_{1}$ & $60 \mathrm{~m}$ & $\mathrm{~d}_{\mathrm{b} 1}, \mathrm{~d}_{\mathrm{b} 2}$ & $100 \mathrm{~m}$ \\
$\mathrm{~h}_{2}$ & $10 \mathrm{~m}$ & $\Gamma_{1}$ & $7 \mathrm{~dB}$ \\
$\mathrm{G}_{1}$ & $10 \mathrm{G}_{2}$ & $\Gamma_{2}$ & $7 \mathrm{~dB}$ \\
\hline
\end{tabular}

Fig.3, Fig.4 and Fig.5 show the total system capacity, the blocking probability, and the dropping probability against the call arrival rate, at $\mathrm{P}_{\mu}=0.5$, the users' velocities are random, $U_{1} \in[0,5] \mathrm{m} / \mathrm{sec}, U_{2} \in[0,2] \mathrm{m} / \mathrm{sec}$, and the users call durations are random, $\mathrm{CT} \in[1,120]$ seconds. The user capacity is increased as $\lambda$ increased, see 
Fig.3, up to a certain arrival rate (approximately $\lambda=10$ users/sec on average) the system capacity is nearly the same and no longer affected by $\lambda$ and became fixed of about 46 users on average. The blocking and the dropping probabilities are both increase as $\lambda$ increases.

For comparison between different system states another set of figures are included, Fig.6, Fig.7, and Fig.8, indicates the system performance at different values of $P_{\mu}$. As expected the user capacity is increased as $\lambda$ increased but for a certain value of $\lambda$ the system capacity is not the same for different $P_{\mu}$, for small values of $\lambda(\lambda<5)$ there is a large difference in the system capacity at different values of $P_{\mu}$. From Fig. 6 , the system capacities on average are $31,42,45$, and 45 at $P_{\mu}=0.9, P_{\mu}=0.75, P_{\mu}=0.25$, and $P_{\mu}=0.5$ respectively, but for higher $\lambda$ there is no significant difference on the total system capacity for all values of $P_{\mu}$.

The blocking probability, as $\lambda$ increases, increases, Fig.7. For small values of $\lambda(\lambda<5)$, the blocking probability at higher $\mathrm{P}_{\mu}$ is roughly about $4 \%$ higher than that at lower $\mathrm{P}_{\mu}$, but for higher values of $\lambda$ the blocking probability is the same for all values of $P_{\mu}$. The dropping probability, Fig.8, also increases as $\lambda$ increases. At small values of $P_{\mu}$ the dropping probability is smaller than that at higher values of $P_{\mu}$, and for higher values of $\lambda$ the dropping probability became roughly fixed for a certain value of $P_{\mu}$

Another set of figures representing the system performance under different values users' velocities is shown at Fig.9, Fig.10 and Fig.11. For small value of users' velocities the system capacity is about $4.5 \%$ higher than that at high velocity, Fig.9. The blocking probability is roughly the same for all values of users' velocity, see Fig.10. On contrary the dropping probability at higher velocities is about $1 \%$ higher than that at small velocities.

The effect of the distance between the two cells, $R_{0}$, on system performance is also examined. Fig.12, Fig.13 and Fig.14, indicate these results. For larger value of $R_{0}$, the system capacity is about $10 \%$ greater than that at small values of $R_{0}$, see Fig. 12 .

\section{Conclusion}

The uplink capacity of a two-cell macro/microcellular CDMA system supporting one type of traffic was examined in terms of the total number of users that can be supported in the system with no constraints on their transmitted power, the blocking , and dropping probabilities. The macrocell was assumed with a square cell layout, and the microcell located in the macrocell is also assumed to be square cell, and a typical radio propagation model to evaluate the effect of various system parameters was used. The system parameters include the user velocity, the hotspot density, and the distance between the macrocell BS and a microcell BS. The dominant parameters affecting the system performance are the users' velocity and the distance between the two cells 


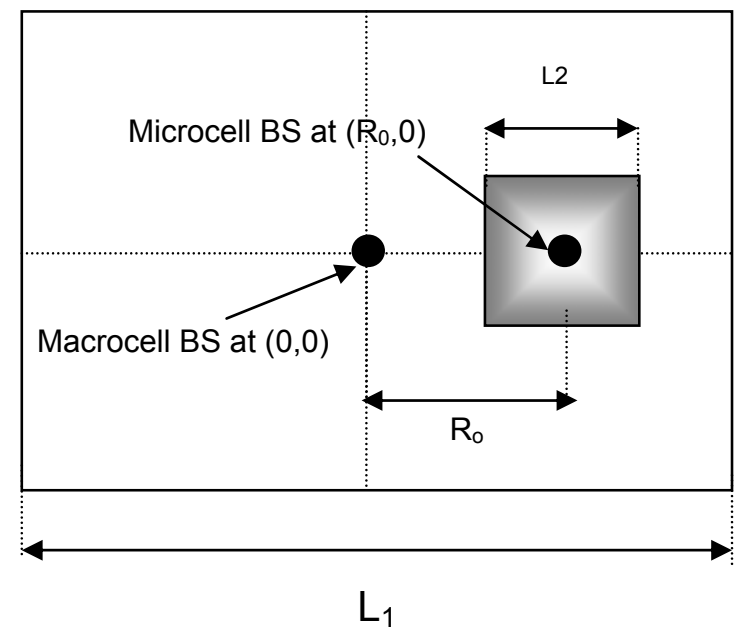

Fig.1, The simulation environment

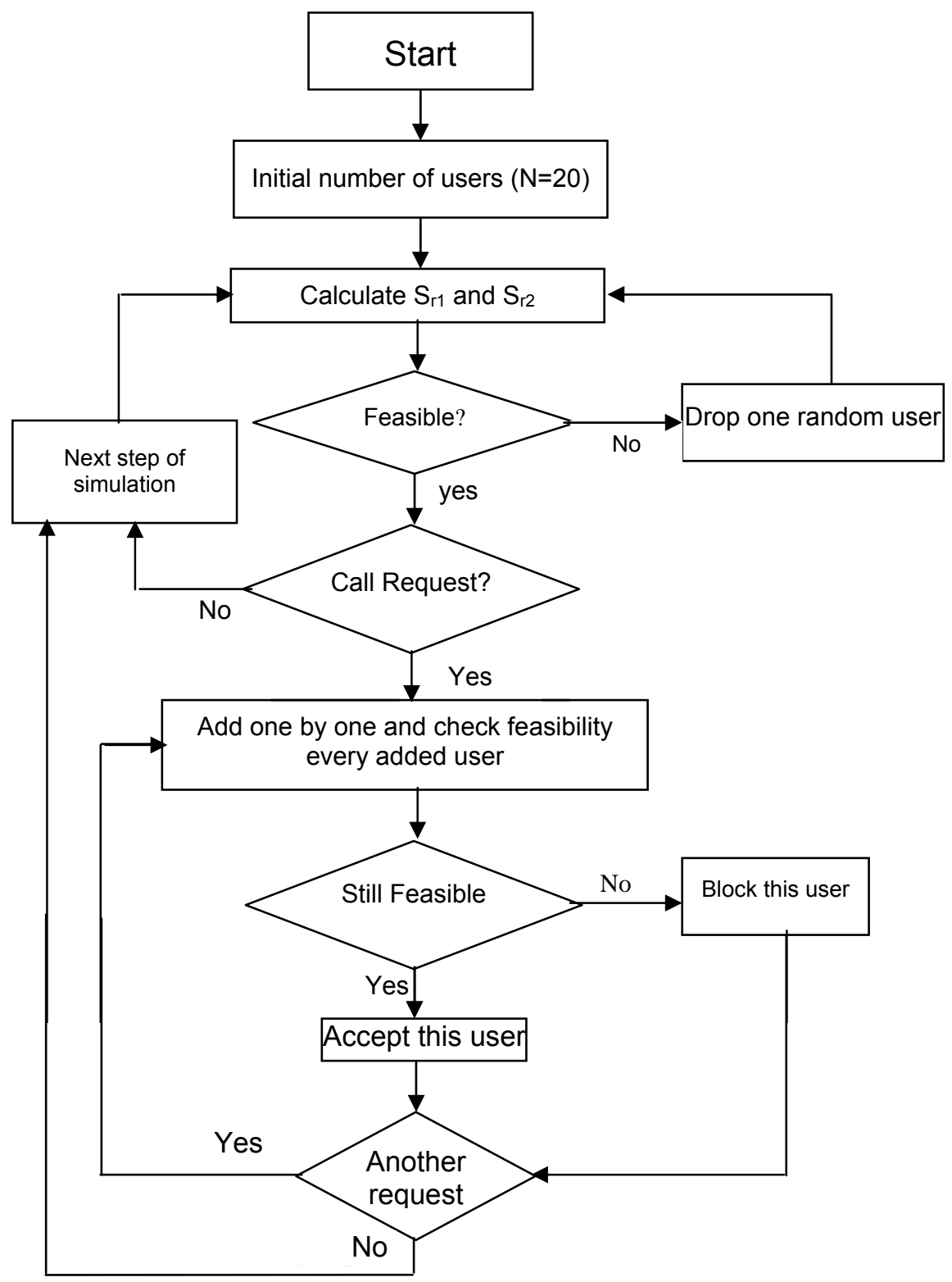

Fig.2, The proposed call admission scheme 


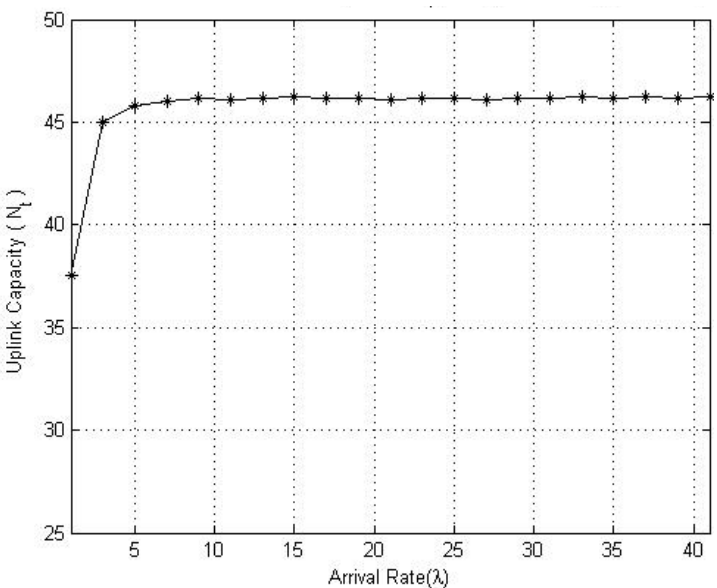

Fig.3, The uplink capacity at different $\lambda, P_{\mu}=0.5$, $\mathrm{u}_{1}=5 \mathrm{~m} / \mathrm{sec}$, and $\mathrm{U}_{2}=2 \mathrm{~m} / \mathrm{sec}$

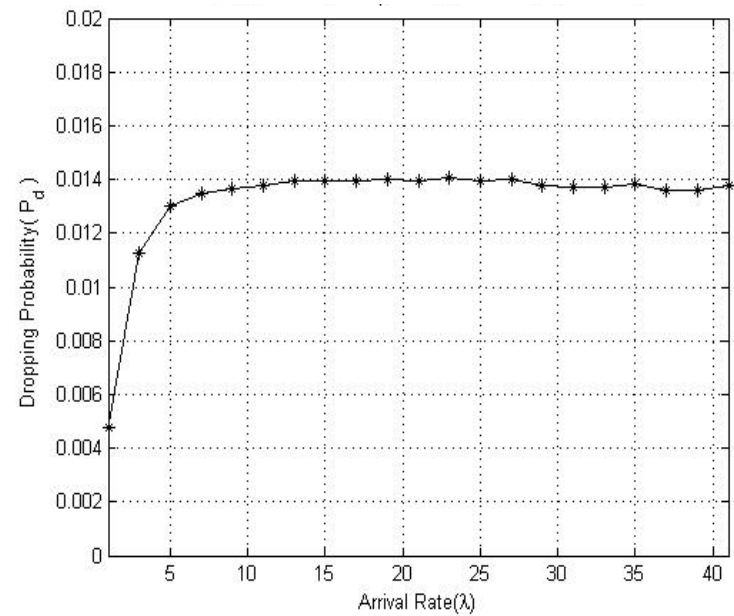

Fig.5, The dropping probability at different $\lambda$ $\mathrm{P}_{\mu}=0.5, \mathrm{u} 1=5 \mathrm{~m} / \mathrm{sec}$, and $\mathrm{u}_{2}=2 \mathrm{~m} / \mathrm{sec}$

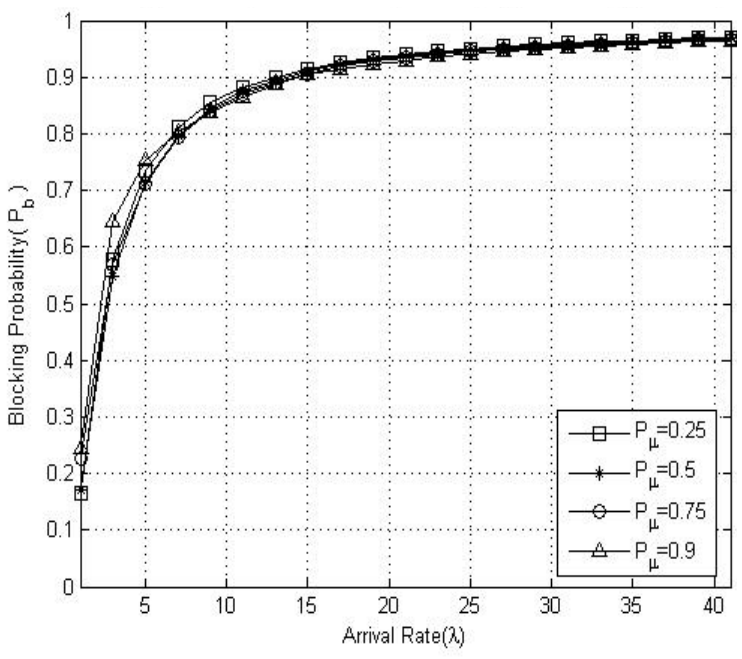

Fig.7, The blocking probability at different $\mathrm{P} \mu$ (u1 $=5 \mathrm{~m} / \mathrm{sec}$, and $\mathrm{u} 2=2 \mathrm{~m} / \mathrm{sec}$ )

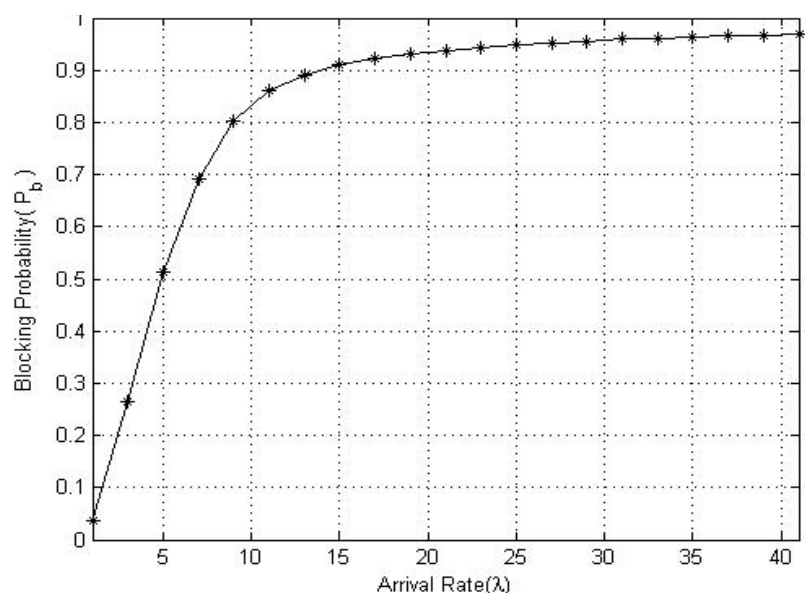

Fig.4, The blocking probability at different $\lambda$, $\mathrm{P}_{\mu}=0.5, \mathrm{u} 1=5 \mathrm{~m} / \mathrm{sec}$, and $\mathrm{U}_{2}=2 \mathrm{~m} / \mathrm{sec}$

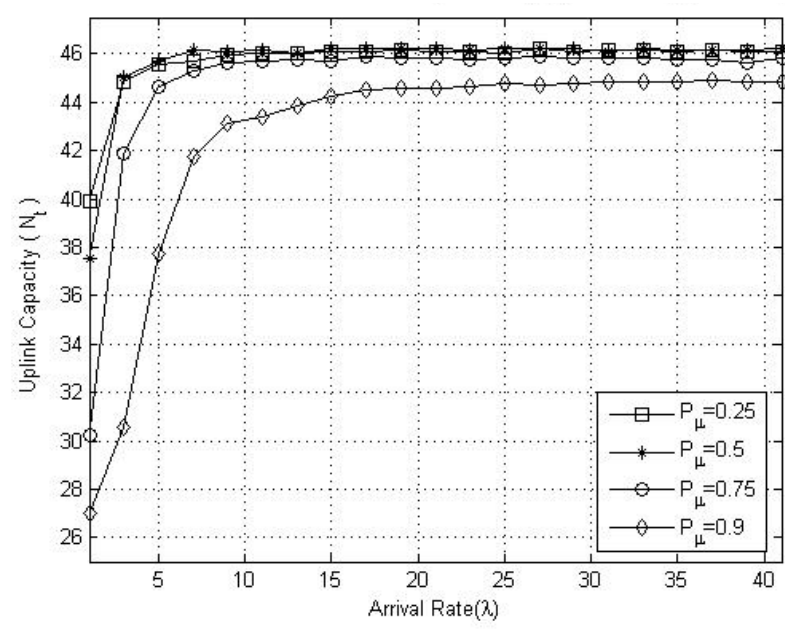

Fig.6, The uplink capacity at different $P_{\mu}$ $\left(\mathrm{u}_{1}=5 \mathrm{~m} / \mathrm{sec}\right.$, and $\left.\mathrm{u}_{2}=2 \mathrm{~m} / \mathrm{sec}\right)$

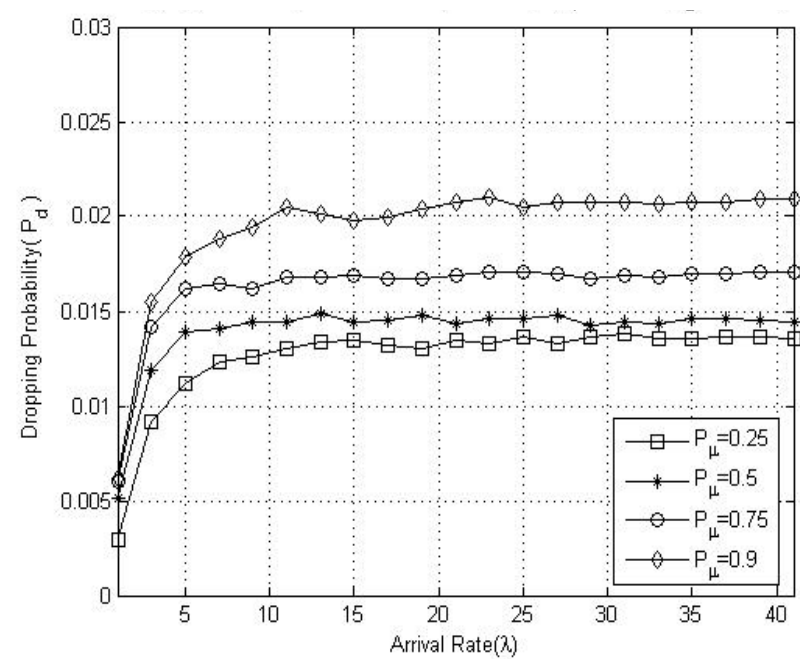

Fig.8, The dropping probability at different $\mathrm{P}_{\mu}$ $\left(\mathrm{u}_{1}=5 \mathrm{~m} / \mathrm{sec}\right.$, and $\left.\mathrm{u}_{2}=2 \mathrm{~m} / \mathrm{sec}\right)$ 


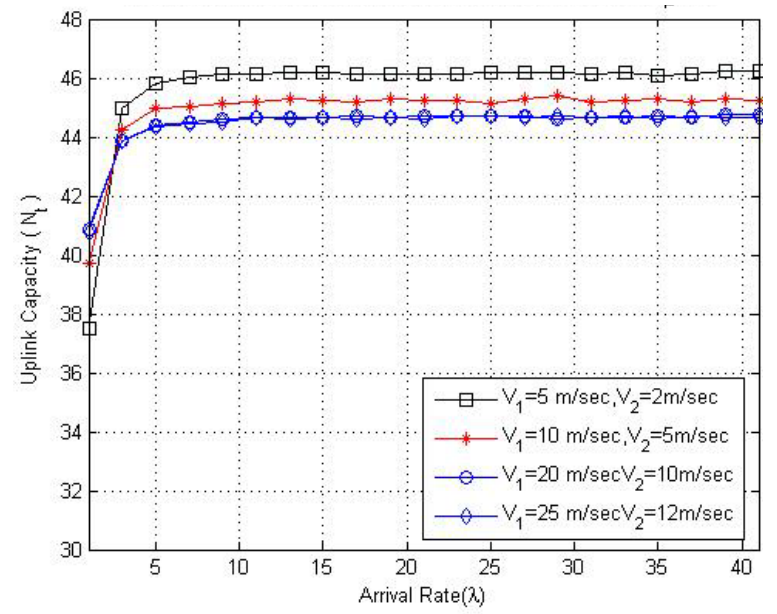

Fig.9, The uplink capacity at $P_{\mu}=0.5$ and different $u$

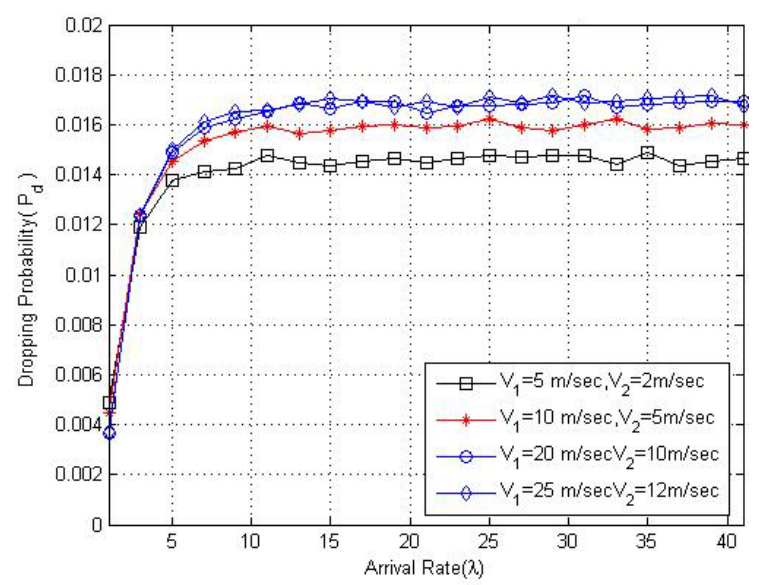

Fig.11, The dropping probability at $P_{\mu}=0.5$ and different $u$

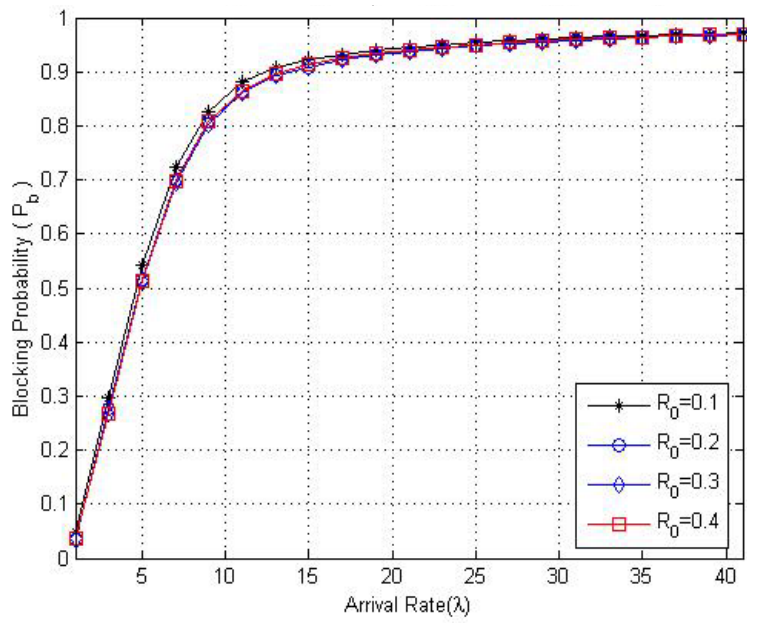

Fig.13, The blocking probability at $P_{\mu}=0.5$ and different $R_{0}$

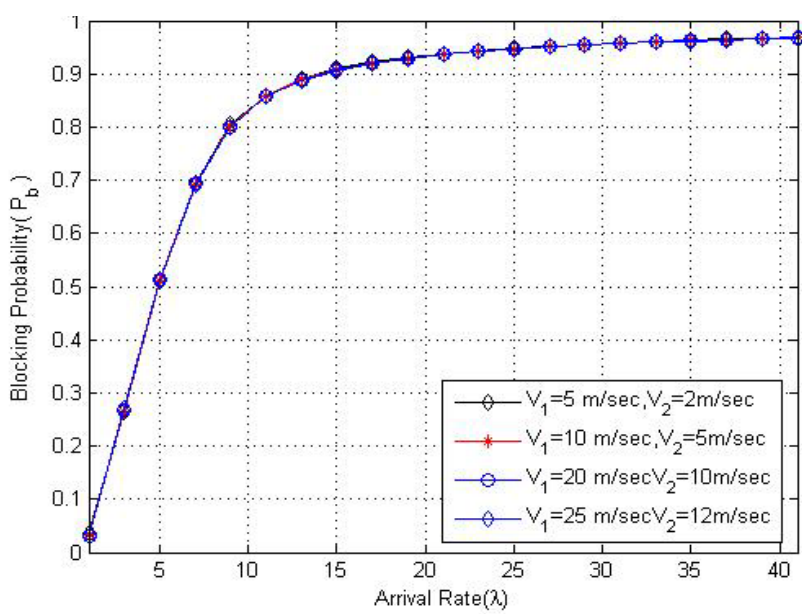

Fig.10, The blocking probability at $P_{\mu}=0.5$ and different $u$

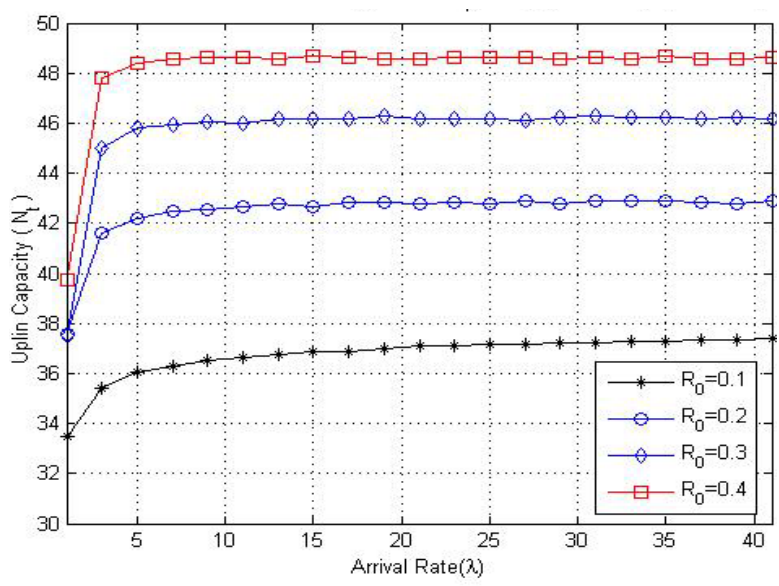

Fig.12, The user capacity at $\mathrm{P}_{\mu}=0.5$ and different $\mathrm{R}_{0}$

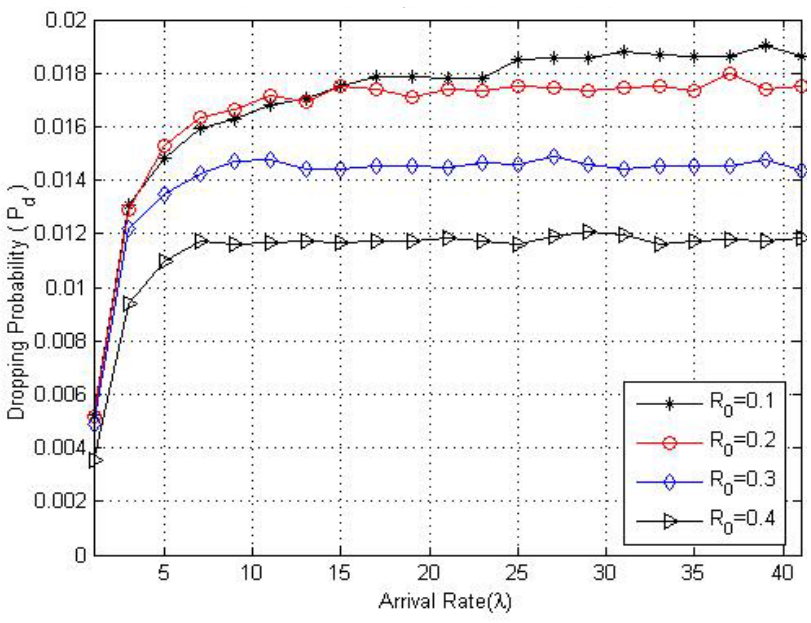

Fig.14, The dropping probability at $P_{\mu}=0.5$ and different $R_{0}$ 


\section{References}

[1] Kishore S., "Capacity and Coverage of Two-Tier Cellular CDMA Networks," Ph.D. Thesis, Dept. of Electrical Engineering, Princeton University, (2003).

[2] Kishore, S., Greenstein, L., Vincent, H. and Schwartz, S., "User Capacity in a CDMA Macrocell with a Hotspot Microcell: Effects of Transmit Power Constraints and Finite Dispersion," IEEE Trans. on Wireless Communications, Vol. 5, No. 2, pp. 417-426, (2006).

[3] Kishore, S., Greenstein, L. , Vincent, H. and Schwartz, S. , "Soft Handoff and Uplink Capacity in a Two-Tier CDMA system" IEEE Trans. on Wireless Communications, Vol. 4, No. 4, pp. 1297-1301,(2005).

[4] Kishore, S., et. al., "Uplink Capacity in a CDMA Macrocell with a Hotspot Microcell: Exact and Approximate Analyses," IEEE Trans. on Wireless Communications, Vol. 2, No. 2, pp. 364-374, (2003).

[5] Kishore, S., et. al, "Downlink User Capacity in a CDMA Macrocell with an Embedded Hotspot Microcell," in Proceedings of Globecom, vol. 3, pp. 15731577, (2003).

[6] Shyr, J., Chung, J., Chuan, Y., "Performance Study for a Microcell Hot Spot Embedded in CDMA Macrocell Systems" IEEE trans. on Veh. Technology Vol. 48, No. 1, pp., 47 - 59, (1999)

[7] Lee, D., Kim, D., Chung, Y., and Whang, K., "Other-cell Interference with Power Control in Macro/Microcell CDMA Networks" Veh. Technology Conference, 'Mobile Technology for the Human Race' IEEE 46th Vol. 2, 28 April-1 May, pp., 1120 - 1124, (1966)

[8] Gilhousen, K., Jacobs, K., Padovani, I., Viterbi, A., Weaver, L., and Weaver, C., "On the capacity of a cellular CDMA system, IEEE trans. on Veh. Technology Vol. 40, pp., 303 - 312, (1991) 